\title{
Release of $\alpha$-actin into serum after skeletal muscle damage
}

\author{
A Martínez-Amat, H Boulaiz, J Prados, J A Marchal, P Padial Puche, O Caba, F Rodríguez- \\ Serrano, A Aránega
}

Br J Sports Med 2005;39:830-834. doi: 10.1136/bjsm.2004.017566

See end of article for authors' affiliations

.....................

Correspondence to: Antonia Aranega, University of Granada, School of Medicine, Department of Morphological Sciences, Granada E-18012, Spain; amat103@ugr.es

Accepted 19 April 2005

\begin{abstract}
Objective: The skeletal muscle protein $\alpha$-actin was investigated in the serum of subjects with severe skeletal muscle damage to assess its utility as a reliable and predictive marker of muscle damage.

Methods: Serum samples were obtained from 33 healthy controls and 33 patients with severe skeletal muscle damage, defined by a total creatine kinase value of $>500 \mathrm{IU} / \mathrm{l}$ (Rosalki method). Troponin I, troponin $\mathrm{T}$, and myoglobin concentrations were determined by immunoassay and $\alpha$-actin concentrations by Western blot and densitometry.

Results: The mean serum concentration of $\alpha$-actin in controls and patients with skeletal muscle damage was 600.9 and $1968.51 \mathrm{ng} / \mathrm{ml}$, respectively, a statistically significant difference. Sera of patients with muscle damage showed higher levels of $\alpha$-actin than of troponin or myoglobin. No significant difference in troponin I levels was observed between the groups.

Conclusions: According to these results, $\alpha$-actin was the most significant skeletal muscle damage marker analysed and may be an ideal candidate for the identification of all types of myofibre injury, including sports injuries. Our findings support the use of $\alpha$-actin as a marker alongside other currently used biological proteins.
\end{abstract}

M uscle injury, defined as injury of skeletal muscle involving the rupture of muscle fibres, is one of the most common reasons for consulting a sports medicine specialist. A training burden that is poorly tolerated by the organism is often the cause of these injuries, ${ }^{12}$ and is the result of an inappropriate training program or the inadequate physical condition of the individual. ${ }^{3}$ The symptoms of muscle damage are polymorphous, non-specific, deceptive, and slow to develop. However, early diagnosis is important, because the sooner treatment is started, the greater the possibility of reversing the symptoms and reducing the severity of muscle damage.

The biological diagnosis of muscle damage is largely based on immunoassay determination ${ }^{4}$ of the serum activity of sarcoplasmic enzymes such as creatine kinase (CK) or lactate dehydrogenase..$^{5-7}$ An increase in the serum activity of these intracellular enzymes reflects their escape through the membrane of injured cells. ${ }^{8}$ However, this method has some drawbacks. First, the findings do not clearly indicate structural muscle damage, as demonstrated by histological studies, ${ }^{10}$ and the speed and reliability of the diagnosis are inadequate. ${ }^{911}$ Second, serum CK levels may not be increased with muscle damage or may only reflect muscle overload. ${ }^{12}$ Finally, the specificity of CK measurement by this method can be reduced by interference from other kinases (for example, adenylate kinase, whose catalytic concentration in plasma is increased by haemolysis), CK isozymes (CKMB or mitochondrial CK), and CK-immunoglobulin complexes known as macrokinases. ${ }^{13}$ Thus, CKMB is co-expressed in both skeletal muscle and the myocardium, and its serum or plasma activity can be increased by muscle alterations when no myocardial necrosis signs are observed by even the most effective imaging methods. ${ }^{14}$

The detection of even small amounts of proteins bound to intracellular structures ${ }^{15}$ (mitochondria, nucleus, cellular contractile apparatus) always indicates necrosis. ${ }^{6}$ Thus, troponins and $\alpha$-actin have been used as biochemical markers of heart damage. Subunits T, C, and I of troponin are proteins of the contractile apparatus found in different isoforms according to the muscle type. ${ }^{16}{ }^{17}$ Thus, cardiac specific isoforms (cTnI) have been used to determine exercise induced heart muscle damage ${ }^{13}$ and myocardial damage during cardioversion of atrial fibrillation, ${ }^{18}$ although their delayed release into the bloodstream severely limits their diagnostic efficiency. ${ }^{19} \alpha$-Actin has been used as a molecular marker of ischaemic heart disease, ${ }^{20-22}$ and studies have confirmed its presence in the sera of patients with unstable angina $^{21}$ as well as its high sensitivity (63-100\%) and earlier release compared with cardiac specific troponins. The effectiveness of $\alpha$-actin as a marker of muscle damage and its abundance in muscle, where it represents $>20 \%$ of all cell proteins, ${ }^{23}{ }^{24}$ make it a promising candidate as a new marker of skeletal muscle damage.

The objective of this preliminary study was to use the Western blot technique to measure the release of skeletal $\alpha$ actin into the serum of patients with severe skeletal muscle damage, discriminating for possible interference by cardiac actin by means of a troponin study of myocardial damage. The sensitivity of Western blot and the biological material used (serum obtained by a simple extraction of blood without need for biopsy) offer two major advantages for the study of skeletal muscle damage. Our results suggest that skeletal $\alpha$ actin may be a specific marker of muscle damage that could be measured when treating elite sportsmen and women. If $\alpha$ actin proves to have diagnostic value, it might allow the development of a fast and easily applied test to assess in situ the severity of skeletal muscular injury in sports people.

\section{METHODS}

\section{Subjects}

Blood samples were obtained from 33 consecutive patients immediately after their arrival at the Emergency Department of the Trauma Centre of the Virgen de las Nieves University Hospital of Granada with skeletal muscle damage caused by severe trauma (accidents, bruises, etc). The patients were aged from 22 to 80 years; 24 were male $(72.7 \%)$ and nine female $(27.3 \%)$, with a mean age of 43.8 and 55 years, respectively. Ethical committee approval had been obtained for the study. Blood samples $(5 \mathrm{ml})$ were extracted with patients' informed written consent. The selection criterion 
Table 1 Determination of levels of CK, troponin (cTnT, cTnl), myoglobin, and $\alpha$-actin in serum

\begin{tabular}{lll}
\hline & Muscle damage group & Control group \\
\hline CK (IU/l) & $2041.9 \pm 2194.5(1015)$ & $105.5 \pm 103.9^{*}(79)$ \\
$\mathrm{Tnl}(\mathrm{ng} / \mathrm{ml})$ & $0.035 \pm 0.031(0.030)$ & $0.0213 \pm 0.0199(0.016)$ \\
$\mathrm{TnT}(\mathrm{ng} / \mathrm{ml})$ & $0.047 \pm 0.075(0.010)$ & $0.0072 \pm 0.0253^{*}(0.001)$ \\
Myoglobin (ng/ml) & $891.815 \pm 887.449(633.1)$ & $28.8697 \pm 24^{*}(18.9062)$ \\
$\alpha$-Actin (ng/ml) & $1968.51 \pm 515.25(2119.5)$ & $600.90 \pm 532.97^{*}(514)$ \\
\hline
\end{tabular}

All data are expressed as mean \pm SEM of four measurements. The significance of the differences $(*)$ between the control and muscle damage groups was determined by the Wilcoxon test. A significant difference was considered when $p<0.001$. The median value is indicated in parentheses.

was the presence of a total CK value of $>500 \mathrm{IU} / \mathrm{l}$ by the Rosalki method (Beckman Instruments, Madrid, Spain).

Control assays were performed in 33 serum samples collected at the Granada Regional Blood Bank from 24 healthy males $(72.7 \%)$ and nine healthy females $(27.3 \%)$ with a mean age of 54.5 and 76.3 years, respectively. These donors ranged in age from 22 to 79 years.

Serum samples were obtained by venopuncture and collected in tubes with separator gel (Venoject II, Terumo Europe, Leuven, Belgium). After clotting, they were centrifuged for $10 \mathrm{~min}$ at $5000 \mathrm{rpm}$ (Beckman Instruments Centrifuge). The sera were then aliquoted into $1.5 \mathrm{ml}$ Eppendorf tubes for the determinations.

\section{Determination of total CK activity}

The enzymatic kinetic method was used to determine total CK activity. In the reaction, the CK catalyses the transfer of a phosphate group from creatine phosphate to adenosine diphosphate. The subsequent formation of adenosine triphosphate is measured by using two associated reactions, catalysed by hexokinase and glucose-6-phosphate dehydrogenase, which produce nicotinamide adenine dinucleotide. This CK assay contains the activator monothioglycerol.

\section{Immunoassay determination of troponin I (cTnI), troponin $\mathrm{T}(\mathrm{cTnT})$, and myoglobin}

Troponin I, troponin $\mathrm{T}$, and myoglobin were determined by chemoimmunofluorescence immunoassay. For troponin I and myoglobin, an Access sandwich-type immunoenzymatic assay (Beckman Instruments) was used. A sample was added to a glass reaction vessel with alkaline phosphatase-conjugated anti-troponin I and anti-myoglobin monoclonal antibodies along with paramagnetic particles coated with anti-troponin I and anti-myoglobin monoclonal antibodies. Cardiac troponin and human myoglobin bind to the antibody in the solid phase, whereas the antibody-alkaline-phosphatase conjugate reacts with different antigenic sites on cardiac troponin and myoglobin molecules. After incubation, separa-

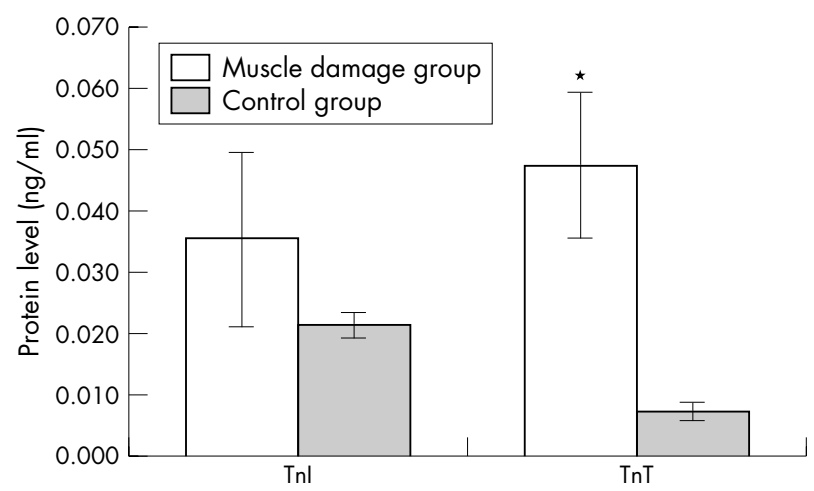

Figure 1 Representation of mean Tnl and TnT levels in control group and muscle damage group sera. *Indicates significant differences between the groups. tion in a magnetic field and washing removes materials not bound to the solid phase. A chemiluminescent substrate, Lumi-Phos 530, was added to the reaction vessel and a luminometer was used to measure the light generated by the reaction. The production of photons is inversely proportional to the amount of enzymatic conjugate present at the end of the reaction and, consequently, to the concentration of cardiac troponin I and myoglobin in the sample. The amount of analyte in the sample was determined using a multipoint calibration curve.

For the troponin $\mathrm{T}$ determination, the Elecsys 2010 troponin $\mathrm{T}$ test (Roche Diagnostic, Indianapolis, IN) was used, which is performed in $18 \mathrm{~min}$ at $37^{\circ} \mathrm{C}$. In a first incubation step, a sandwich-type complex was formed by the sample, a specific biotinylated monoclonal antibody against troponin $\mathrm{T}$, and a ruthenium chelate labelled (chelate tris $\left(2,2^{\prime}\right.$-bipyridul)ruthenium(II), $\quad(\mathrm{Ru}(\mathrm{bpy}) 2+3) \quad$ specific monoclonal antibody against troponin $\mathrm{T}$.

\section{Detection of $\alpha$-actin by Western blot}

Sarcomeric $\alpha$-actin was determined by Western blot. A sample of serum $(5 \mu \mathrm{l})$ from each study subject was dissolved in Laemmli's sample buffer $(62.76 \mathrm{~mm}$ Tris-HCl pH 6.8, $1 \%$ 2-mercaptoethanol, $1 \%$ SDS, $10 \%$ glycerol, and $0.01 \%$ bromophenol blue) at 1:5 ratio, boiled for $5 \mathrm{~min}$, microfuged for $1 \mathrm{~min}$, and analysed by SDS-PAGE (sodium dodecylsulphate polyacrylamide gel electrophoresis) in a Mini Protean II cell (Bio-Rad, Hercules, CA) at $60 \mathrm{~mA}$ for $\mathrm{l} \mathrm{h}$ at room temperature. The gels with samples of serum were run in duplicate in all cases. The gels for immunoblot analyses were separated electrophoretically and transferred to a nitrocellulose membrane by applying a current of $20 \mathrm{~V}$ at room temperature for $30 \mathrm{~min}$. The blots were treated with blocking solution (20 mM Tris, $0.9 \mathrm{NaCl}, 10 \%$ non-fat milk) for $3 \mathrm{~h}$ at room temperature and then reacted with a 1:2000 dilution of anti-sarcomeric $\alpha$-actin monoclonal antibody (Alpha-Sr- 1 Clones, Dako, Glostrup, Denmark). Primary antibodies were incubated overnight at $4^{\circ} \mathrm{C}$. Membranes were washed ( $15 \mathrm{~min}$ in 5\% TBST) and incubated with horseradish peroxidase conjugated rabbit anti-mouse $\operatorname{IgG}$ (1:2000, Sigma-Aldrich, St Louis, MO) for $\mathrm{l} \mathrm{h}$ at room temperature, followed by additional washes ( $15 \mathrm{~min}$ in $5 \%$ TBST). Proteins were visualised by enhanced chemiluminescence (ECL, Bonus, Amersham, Little Chalfont, UK).

\section{Densitometric analysis of $\alpha$-actin}

Densitometric analysis was carried out by scanning $x$ ray images of the membranes (Fluorine-S Multimager, Bio-Rad). The resolution of the images was 100 pixels per inch. A densitometry image analysis software package (Quantity l, Bio-Rad) was used. The procedure was repeated for every sample processed in this study. A digital image was obtained formed by 66 wells, 33 with control group and 33 with skeletal muscle damage group samples.

A standard curve was obtained by immunoblotting with an amount of known proteins (nanograms of pure $\alpha$-actin) and densometrically quantifying the bands obtained. 


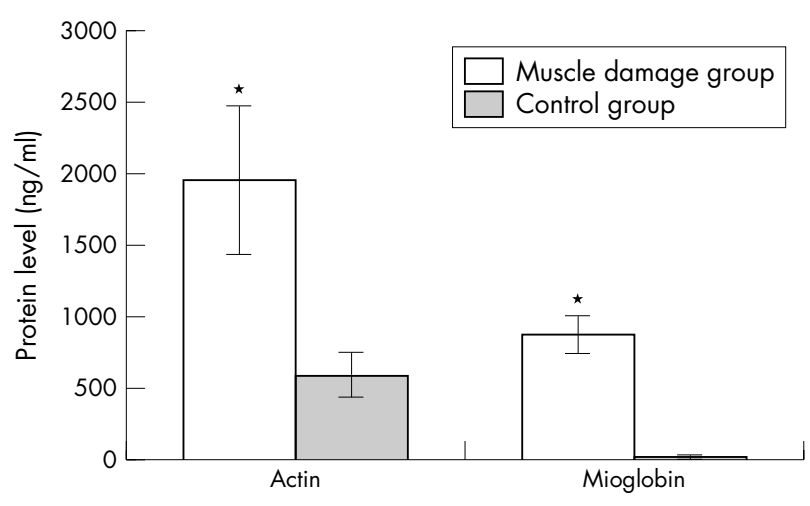

Figure 2 Representation of mean $\alpha$-actin and myoglobin levels in control group and muscle damage group sera. *Indicates significant differences between the groups.

\section{Statistical analysis}

Because only $\alpha$-actin followed a normal distribution among the variables studied, a non-parametric Wilcoxon test was applied to all variables. Student's $t$ test was used to compare $\alpha$-actin concentrations between the groups. Data were entered into a personal computer and statistical procedures were performed using the SPSS statistical package (v. 11.5; SPSS, Chicago, IL). Statistical significance was preset at the $\mathrm{p}<0.001$ level.

\section{RESULTS}

Sera of the muscle damage group showed a mean CK activity in serum of 2041.9 IU/l (range: 517-8943 IU/1), significantly $(\mathrm{p}<0.001)$ higher than the level of 105.5 IU/1 (range: 15$545 \mathrm{IU} / \mathrm{l}$ ) found in the control group sera (table 1).

The muscle damage group showed a mean troponin I (cTnI) value of $0.035 \mathrm{ng} / \mathrm{ml}$ (range: $0.001-0.160 \mathrm{ng} / \mathrm{ml}$ ) compared with $0.0213 \mathrm{ng} / \mathrm{ml}$ (range: $0.001-0.085 \mathrm{ng} / \mathrm{ml}$ ) for the control group, a non-significant difference (fig 1). There was a significance $(\mathrm{p}<0.001)$ difference between the mean value of troponin $\mathrm{T}(\mathrm{cTnT})$ in the muscle damage group $(0.047 \mathrm{ng} / \mathrm{ml}$; range: $0.001-0.220 \mathrm{ng} / \mathrm{ml})$ and that in the control group $(0.0072 \mathrm{ng} / \mathrm{ml}$; range: $0.001-0.139 \mathrm{ng} / \mathrm{ml})$ (table 1).

A mean myoglobin value of $891.815 \mathrm{ng} / \mathrm{ml}$ (range: $3.633-$ $58.6 \mathrm{ng} / \mathrm{ml}$ ) was detected in the muscle damage group sera, significantly $(\mathrm{p}<0.001)$ higher than the value of $28.869 \mathrm{ng} / \mathrm{ml}$ (range: $79.8-5.7 \mathrm{ng} / \mathrm{ml}$ ) found in the control sera (table $\mathrm{l}$, fig 2).

Circulating $\alpha$-actin was detected by immunoblotting as a band located at $43 \mathrm{kDa}$ (fig 2). The serum protein concentration was determined by densitometric study of the $\alpha$-actin bands. The mean serum $\alpha$-actin level in the muscle damage group was $1968.51 \mathrm{ng} / \mathrm{ml}$ (range: 854-2.594 ng/ml), significantly $(\mathrm{p}<0.001)$ higher than the concentration of $600.90 \mathrm{ng} / \mathrm{ml}$ (range: $0.00-1.359 \mathrm{ng} / \mathrm{ml}$ ) in the control group (table 1, fig 3 ).

\section{DISCUSSION}

Major questions have been raised in sports medicine about the diagnosis of skeletal muscular damage. Are there any faithful, reliable, sensitive, and reproducible markers of muscular injury? Do variations in these biological markers correlate with the severity of histologic injury? Are increases in these markers associated with overtraining? There appears only to be a consensus that intense physical exercise induces injury of the muscle fibres, and that the severity of these injuries depends on the duration of the exercise, its characteristics, and the training level of the individual. ${ }^{25}$

Clinical assessment of exercise induced muscle injuries is very difficult. The severity and evolution of these structural injuries are highly variable, and they are characterised by simple residual pains in muscle masses and sometimes by a persistent sensation of heaviness in the lower limbs. ${ }^{1}$ Because the clinical expression of this pathology is non-specific, its impact in sports remains difficult to estimate. ${ }^{19}$

The ideal marker should be muscle specific with a high intracellular concentration, and it should be rapidly released in the event of injury and be stable, maintaining its elevated concentration in blood for an adequate time period. It should have a high diagnostic sensitivity, especially in the first few hours after the injury, and have a diagnostic specificity as close to $100 \%$ as possible. ${ }^{14}$

Variation in CK activity is currently used as an indicator of muscle damage. ${ }^{1627}$ The present study demonstrated differences in total CK activity between healthy individuals and those with muscle damage. However, Kuipers and Keizer concluded that it can never be considered a reliable marker of muscle damage, because the presence of total CK in plasma does not faithfully reflect the extent and nature of muscle injury $^{10}$ due to interferences produced by isozymes (CKMM, CKMB, and CKBB) of different origin. Bigard ${ }^{19}$ reported that the extent of exercise induced muscle damage cannot be assessed solely on the basis of variations in CK activity. The lack of sensitivity and reproducibility of CK activity has led to

A
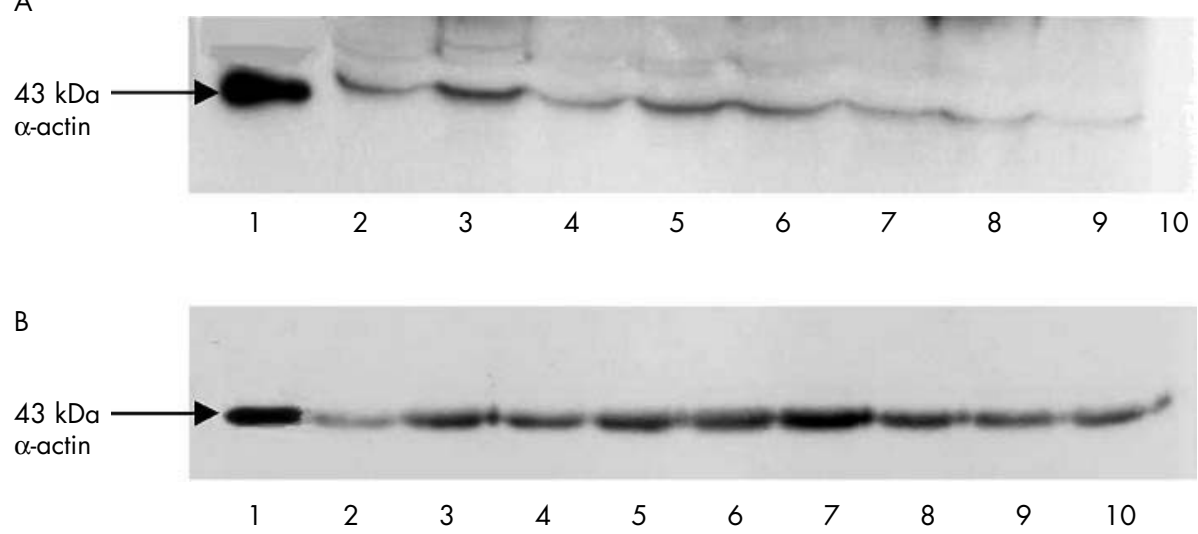

Figure 3 (A) Immunoblotting determination of $\alpha$-actin levels in control group sera (healthy subjects), with a band at the level of $43 \mathrm{kDa}$. Number 1 corresponds to the positive control ( $80 \mathrm{ng} / \mu \mathrm{l}$ of pure $\alpha$-actin) and numbers $2-10$ to the levels of $\alpha$-actin in sera of healthy subjects. (B) Levels of $\alpha$-actin in sera of patients with skeletal muscle damage. Number 1 correspond to the positive control ( $80 \mathrm{ng} / \mu \mathrm{l}$ of pure $\alpha$-actin), and numbers $2-10$ to the levels of $\alpha$-actin in sera of subjects with skeletal muscle damage. 


\section{What is already known on this topic}

Biological diagnosis of muscle damage is based on immunoassay determination of the serum activity of sarcoplasmic enzymes. The detection of even small amounts of proteins bound to intracellular structures always indicates necrosis. Thus, troponins and $\alpha$-actin have been used as biochemical markers to detect heart damage. Troponin isoforms (cTnl and cTnT) are confirmed as heart damage markers but are not useful as skeletal muscle damage markers.

a prudent attitude towards the utility of this biological parameter.

Troponins are used as markers of heart muscle damage. ${ }^{28} 29$ We observed significant differences in serum cTnT levels between healthy and muscle damaged individuals but no significant differences were observed in cTnI values. Various authors have confirmed the specificity of the $\mathrm{CTnI}^{13}{ }^{17}$ and $\mathrm{CTnT}^{30}$ isoforms as heart damage markers but their detection after skeletal muscle damage has not been considered useful. On the other hand, due to its cardiac specificity, cTnI can be used to differentiate between heart and skeletal muscle injuries, ${ }^{31}$ avoiding false positives and increasing the reliability of results.

Muscle damage markers used to date are not sufficiently sensitive for early detection, and the muscle protein $\alpha$-actin may serve this purpose. It is abundant in the cytosolic compartment of the cell, ${ }^{32}$ unlike other proteins such as troponin (there are seven monomers of $\alpha$-actin for each molecule of troponin), ${ }^{33}$ and it can be detected up to $72 \mathrm{~h}$ after its release. ${ }^{34}$ Moreover, $\alpha$-actin is detected $\mathrm{l} h$ after the onset of muscle damage symptoms, whereas troponin is released late into the bloodstream. ${ }^{20} 21$

Our study has demonstrated the utility of this protein to detect skeletal muscle injury, with statistically significant $(\mathrm{p}<0.001)$ differences in serum $\alpha$-actin levels between individuals with muscle damage and controls. These results can be applied in sports medicine because, according to Féasson, ${ }^{35}$ exercise does not induce variations in $\alpha$-actin levels. Therefore, the detection by Western blot of circulating $\alpha$-actin in patients with skeletal muscle damage may reflect cell damage. Although based on a heterogeneous study sample, the results obtained represent preliminary evidence of the value of $\alpha$-actin as an early marker of muscular damage.

In conclusion, our results indicate that $\alpha$-actin may be a good marker to be applied alongside other currently used biological markers for the early identification and diagnosis of skeletal muscle damage. The key characteristics of $\alpha$-actin for this purpose are its abundant presence and stability over time.

\section{Authors' affiliations}

A Martínez-Amat, J A Marchal, F Rodríguez-Serrano, Department of Health Sciences, University of Jaén, E-23071 Jaén, Spain H Boulaiz, J Prados, O Caba, A Aránega, Basic Cardiovascular Research Section, Department of Morphological Sciences, School of Medicine, University of Granada, E-18012 Granada, Spain

P Padial Puche, Faculty of Sciences of Physical Activity and Sports, Department of Physical and Sports Education, University of Granada, E18220 Granada, Spain

This study was supported by the Andalusian Sports Medicine Center (C.A.M.D.) through project no. 2003/319563

Competing interests: none declared
What this study adds

$\alpha$-Actin is an abundant protein in the muscle, where it represents $>20 \%$ of all cell proteins. In this study, we demonstrate $\alpha$-actin efficiency as a marker of muscle damage suggesting its potential use as a new marker of skeletal muscle damage. As our results show, $\alpha$-actin was the most significant skeletal muscle damage marker analysed. We therefore propose it as candidate for the identification of all types of myofibre injury.

\section{REFERENCES}

1 Clarkson PM, Hubal MJ. Exercise-induced muscle damage in humans. Am J Phys Med Rehabil 2002;81:52-69.

2 Rodenburg JB, Bar PR, De Boer RW. Relations between muscle soreness and biochemical and functional outcomes of eccentric exercise. J Appl Physiol 1993;74:2976-83.

3 Kenttä G, Hassmén P. Overtraining and recovery. A conceptual model. Sports Med 1998;26:1-16.

4 Masamichi OI, Maeda T. Separation techniques for high molecular mass proteins. J Chromatogr B 2002;771(5):49-66

5 Gleeson M, Walsh NP, Blannin AK, et al. The effect of severe eccentric exercise-induced muscle damage on plasma elastase, glutamine and zinc concentrations. Eur J Appl Physiol 1998;77(6):543-6.

6 Santaló M, Guindo J, Ordóñez J. Marcadores biológicos de necrosis miocárdica. Rev Esp Cardiol 2003;56(7):703-20.

7 Takagi Y, Yasuhara T, Gomi K. Creatine kinase and its isozymes. Rinsho Byori $2001 ; 116: 52-61$.

8 Kayashima S, Ohno H, Fujioka T, et al. Leucocytosis as a marker of organ damage induced by chronic strenuous exercise. Eur J Appl Physiol 1995; 70:413-20

9 Prou E, Margaritis I, Tessier F, et al. Effects of strenuous exercise on serum myosin heavy chain fragments in male athletes. Int J Sports Med 1996; 17:263-7.

10 Kuipers H, Keizer HA. Overtraining in elite athletes: review and directions for future. Sports Med 1988;6:79-92.

11 Clarkson PM, Byrneswc M, Mccormick KM, et al. Muscle soreness and serum creatine kinase activity following isometric, eccentric and concentric exercise. Int J Sports Med 1996;7:152-5.

12 Komulainen J, Takala T, Vihko V. Does increased serum creatine kinase activity reflect exercise-induced muscle damage in rats? Int J Sports Med 1995; 16:150-4.

13 Shave R, Dawson E, Whyte $G$, et al. Markers of cardiac damage after two days of prolonged endurance exercise. J Sport Sci 2002;20(1):58.

14 Adams JE, Abendschein DR, Jaffe AS. Biochemical markers of myocardial injury. Is MB creatine kinase the choice for the 1990s? Circulation 1993;88:750-63.

15 Carroll CC, Carrithers JA, Trappe TA. Contractile protein concentrations in human single muscle fibers. J Muscle Res Cell Motil 2004;25(1):55-9.

16 Takahashi $M$, Lee $L$, Shi $Q$, et al. Use of enzyme immunoassay for measurement of skeletal troponin-I utilizing isoform-specific monoclonal antibodies. Clin Biochem 1996;29(4):301-8.

17 Thuraia N, Sherwood RA, Harris BM, et al. Cardiac troponin T and I and creatine kinase- $M B$ as markers of myocardial injury and predictors of outcome following percutaneous coronary intervention. Int J Cardiol 2003;92:285-93.

18 Kosior D, Chwyczko T, Stawicki S, et al. Myoglobin and troponin I as markers of myocardial damage during cardioversion of atrial fibrillation. Pol Arch Med Wewn 2003; 1 10:827-36.

19 Bigard AX. Exercise-induced muscle injury and overtraining. Sci Sport $2001 ; 16: 204-15$

20 Aránega AE, Reina A, Muros MA, et al. Circulating alpha-actin protein in acute myocardial infarction. Int J Cardiol 1993;38(1):49-55.

21 Aránega $\mathrm{AE}$, Reina $\mathrm{A}$, Velez $\mathrm{C}$, et al. Circulating $\alpha$-actin in angina pectoris. J Mol Cell Cardiol 1993;29:15-22.

22 Aránega AE, Velez C, Prados J, et al. Modulation of a-actin and a-actinin proteins in cardiomyocytes by retinoic acid during development. Cells Tissues Organs 1999;164:82-9.

23 Grazi E, Cintio O, Trombetta G. On the mechanics of the actin filament: the linear relationship between stiffness and yield strength allows estimation of the yield strength of thin filament in vivo. J Muscle Res Cell Motil 2004;25(1):103-5.

24 Machesky LM, May RC. Arps: actin-related proteins. Results Probl Cell Differ $2001 ; 32: 213-29$

25 Asp S, Daugaard JR, Kristiansen S, et al. Eccentric exercise decreases maximal insulin action in humans: muscle and systemic effects. J Physiol 1996;494:891-8.

26 Gomes AV, Potter JD, Szczesna-Cordary D. The role of troponins in muscle contraction. IUBMB Life 2002;54:323-33.

27 Kopp J, Loos B, Spilker G, et al. Correlation between serum creatinine kinase levels and extent of muscle damage in electrical burns. Burns 2004;30(7):680-3 
28 Nesher N, Zisman E, Wolf $\mathrm{T}$, et al. Strict thermoregulation attenuates myocardial injury during coronary artery bypass graft surgery as reflected by reduced levels of cardiac-specific troponin I. Anesth Analg 2003;96:328-35.

29 Xing $Y$, Huang $P$, Zhang K. Cardiac troponin T and I: application in

myocardial injury and forensic medicine. Fa Yi Xue Za Zhi 2003;19:242-4.

30 Shave R, Dawson E, Whyte G, et al. The cardiospecificity of the thirdgeneration cTnT assay after exercise-induced muscle damage. Med Sci Sport Exerc 2002;34(4):651-4.

31 Sorichter S, Mair J, Koller A, et al. Skeletal troponin I as a marker of exerciseinduced damage. J Appl Physiol 1997;83:1076-82.
32 Goodson HV , Hawse WF. Molecular evolution of the actin family. J Cell Sci 2002;115:2619-22.

33 Katus HA, Looser S, Hallermayer K, et al. Development and in vitro characterization of a new immunoassay of cardiac troponin T. Clin Chem 1992;38(3):386-93.

34 Korn, ed. Actin polymerization and its regulation by proteins from non muscle cells. Physiol Rev 1982;62:672-737.

35 Féasson L, Stockholm D, Freyssenet D, et al. Molecular adaptations of neuromuscular disease-associated proteins in response to eccentric exercise in human skeletal muscle. J Physiol 2002;543(1):297-306.

\section{bmjupdates+}

bmjupdates+ is a unique and free alerting service, designed to keep you up to date with the medical literature that is truly important to your practice.

bmjupdates+ will alert you to important new research and will provide you with the best new evidence concerning important advances in health care, tailored to your medical interests and time demands.

Where does the information come from?

bmjupdates+ applies an expert critical appraisal filter to over 100 top medical journals A panel of over 2000 physicians find the few 'must read' studies for each area of clinical interest

Sign up to receive your tailored email alerts, searching access and more...

www.bmjupdates.com 